Original article

\title{
The hepatocellular carcinoma's risk factors among in-hospital patients at the university-teaching hospital Yalgado Ouédraogo in Ouagadougou, Burkina Faso: A case-control study
}

\author{
Eric Nagaonlé Somé ${ }^{a, *}$, Nanelin Alice Guingané ${ }^{\mathrm{b}}$, Hermann Ouédraogo ${ }^{\mathrm{c}}$, Grissoum Tarnagda ${ }^{\mathrm{a}}$, \\ Séni Kouanda ${ }^{\mathrm{a}}$, Roger Sombié ${ }^{\mathrm{b}}$
}

${ }^{a}$ Institut de recherche en sciences de la santé (IRSS) CNRST Ouagadougou, Burkina Faso

${ }^{\mathrm{b}}$ Département de gastro-entérologie, UFR/SDS, Université Joseph Ki-Zerbo, Ouagadougou, Burkina Faso

${ }^{\mathrm{c}}$ Département d'orthopédie-traumatologie, UFR/SDS, Université Joseph Ki-Zerbo, Ouagadougou, Burkina Faso

\section{A R T I C L E I N F O}

\section{Keywords:}

Hepato-cellular carcinoma

Primary liver cancer

Hepatitis B infection

Risk factor

Sub Saharan Africa

\begin{abstract}
A B S T R A C T
Introduction: The hepatocellular carcinoma (HCC) remains one of the most frequent cancers in Africa. Our objective was to identify the risk factors of the primary liver cancer occurrence among hospitalized patients in the gastro-enterology unit of the university teaching hospital Yalgado Ouédraogo.

Methods: We implemented a case-control study and collected data from January 1, 2012 to the December 31, 2015. Controls were recruited among blood donors. Cases were selected among patients visiting the gastroenterology unit of the Yalgado Ouédraogo Hospital. Cases were matched to the controls using age and sex variables. In our multivariate logistic regression model, the outcome variable was the occurrence of the liver cancer. The main independent variable was the chronic carriage of HbsAg.

Results: We included 92 cases and 92 controls. The sex ratio was 3. Chronic carriage of HBsAg was diagnosed among $14.13 \%$ and $76 \%$ of controls and cases, respectively. The anti-HCV Ab test was positive in $15.22 \%$ of the cases and $4.35 \%$ of the controls. Being 50 years or older, HbsAg chronic carrier, farmer or working in the informal sector or living in a provincial capital were the main statistically significant risk factors to develop primary liver cancer.

Conclusion: In Burkina-Faso, liver cancer patients reached out to hospital very late. Our best tools to reduce the incidence and the mortality due to the primary liver cancer include immunizing largely against the HBV infection taking into account the birth dose; and managing adequately the cases of HBV and HCV infections.
\end{abstract}

\section{Introduction}

The hepatocellular carcinoma (HCC) remains one of the most frequent cancers in Africa. ${ }^{1,2}$ Globally, the chronic carriage of the hepatitis B virus (HBV) or hepatitis C virus (HCV) are major etiological factors of liver cancers. The HBV infection would be responsible of half of all cases of HCC. ${ }^{3}$ The statistics show that there are 350 million HBV chronic carriers from a total of 2 billion infected people. Sub Saharan Africa and East Asia are ranked among the highest prevalence zones where $10 \%$ of the population are chronic carriers. HBV infection share the same vulnerable groups with the HIV infection, which include injectable drug users, men who have sex with men, hemodialysis patients, health care workers and children born to mothers carrying the surface antigen of the HBV (HbsAg positive). ${ }^{2,4,5}$

In Burkina Faso, according to GLOBOCAN, the primary liver cancer would be the third most frequent cancer (following the cervical and breast cancer). It would be the second cause of mortality by cancer following the cervical cancer. ${ }^{6}$ In 2007 , according to hospitals' data, the primary liver cancer represented $78.7 \%$ of all cancers and $70 \%$ of mortality at the University Teaching Hospital (UTH) Sanou Souro in Bobo-Dioulasso, (main hospital of the second biggest city in Burkina Faso). In 2014, 25.3\% of the hospitalizations in the

; HbsAg, Hepatitis B surface Antigen; HBV, hepatitis B virus; HCC, hepatocellular carcinoma; HCV, hepatitis C virus; OR, Odd Ratio; UOR, unadjusted odd ratio; WHO, World Health Organization; Anti-HCV Ab, Anti-HCV Antibody.

* Corresponding author. 10 BP 250 Ouagadougou 10, Burkina Faso.

E-mail address: eric.some@gmail.com (E.N. Somé). 
hepato-gastro-enterology unit of the UTH Yalgado Ouédraogo (the main hospital in Ouagadougou the capital city of Burkina Faso) was prompted by primary liver cancer. These statistics may be largely under-estimated because many patients die at home, of liver cancer without any formal diagnosis nor any contact with a health care facility.

In 2014, the WHO regional committee for Africa adopted a resolution to control the HBV infection by reducing the prevalence of the chronic carriage among children less than 5 -year old to less than $2 \%$ in the member-countries by $2020 .^{7,8}$ The ultimate target of this plan is to drop the mortality related to HBV and HCV infections from four million to less than 500000 in 2030 (65\% reduction for both HBV and HCV). The main complications of HBV and HCV infections responsible of most of the deaths are cirrhosis and primary liver cancers. In addition to the HBV and HCV infections, we anticipate as other studies, ${ }^{1,9}$ that the patient's age, residence and socio-economic status are also important risk factors for HCC. Our objective was to assess the magnitude of HBV infection as a contributor to the HCC occurrence among hospitalized patients in the gastro-entérology unit of the UTH Yalgado Ouédraogo.

\section{Patients and methods}

\subsection{Study design and population}

We implemented a case-control study. Data was collected retrospectively from the January 1, 2012 to the December 31, 2015. Controls were recruited among blood donors at the Ouagadougou regional transfusion centre. Cases were selected among patients visiting the gastro-enterology unit of the UTH Yalgado Ouédraogo. Cases were matched to the controls using age and sex variables.

The case was defined as any in-hospital patient with a liver disease:

- presenting features of malignancy at the physical assessment

- for which the ultrasound, the T scan or the magnetic resonance imaging showed suspicious lesions of hepatocellular carcinoma;

- associated with a concentration of alpha-foeto-protéin $\geq$ à $500 \mathrm{ng}$ / $\mathrm{ml}$;

- or for which the pathology analysis found malignant cells.

Were included all cases whatever the age and sex, with no previous history of cancer of another kind or organ diagnosed within the past decade. Pregnant women were excluded. Were also included the controls of same age group and sex whenever feasible, knowing that 60 -year old and above subjects are not allowed to donate blood. Finally we excluded all cases and controls for whom relevant data were missing.

\subsection{Sample size, data collection and analysis}

We used the open-epi platform to calculate the sample size (https:// www.openepi.com/MatchCC/MatchCC.htm). The total sample size was 184 participants, distributed between cases and controls (92 participants for each group) based on the hypothesis of a case/control ratio of 1 , a power of $80 \%$, an alpha margin of $5 \%$ and an odd ratio of 3 . The population exposure rate to $\mathrm{HBsAg}$ was $11.4 \% .{ }^{10}$ The data were collected using a form. The relevant variables included socio-demographic characteristics, personal and family history of cancer and other diseases, the lifestyle and risk behaviour with respect to cancer occurrence, clinical, biological and imaging characteristics, the cases management and the progression of the disease.

We first implemented a univariate analysis on the relevant variables, displaying means and proportions. The bivariate analysis identified the independent variables associated with the liver cancer occurrence by calculating the unadjusted odd ratios. Finally we run a multivariate logistic regression. The dependant variable was the occurrence of the liver cancer (yes/no). The principal independent variable was the chronic carriage of HbsAg (yes/no). The initial model accepted variables when $\mathrm{p}$ $\leq 0.2$. We also assessed the potential interaction and confusion factors.
The final model was selected using a backward step regression. The variables showing the biggest $\mathrm{p}$ were withdrawn at each step. At this phase of the selection, $p$ was considered significant when $p \leq 0.05$. The fitness of the models were tested using the Akaike information criteria (AIC). We used Stata/SE V.13.1 to run the analyses.

\subsection{Ethics}

We implemented this study as part of the programme of a medical doctorate thesis. We anonymised all collected data and obtained all required authorizations from the hospital management team. It was a retrospective collection of routine data of the gastro-enterology and the blood bank units. The student in charge of the data collection was briefed on how to maintain confidentiality while collecting the data from the source documents.

\subsection{Study results}

We investigated 830 patients' files at the gastro-enterology unit and 1080 files at the regional blood bank office. 184 participants were included of which 92 cases and 92 controls. Table 1 shows the sociodemographic characteristics as well as the qualitative clinical data for both cases and controls.

The most represented age group was the one between 35 and 50 years for the controls and cases, representing $58.70 \%$ et $42,39 \%$ respectively. The sex ratio was 3 . Farming or working in the informal sector were predominant employment among cases while the majority of controls used to work in more formal public or private sector. $86.96 \%$ of controls originated from Ouagadougou as compared to $46.74 \%$ of cases. Chronic carriage of HBsAg was diagnosed among $14.13 \%$ and $76 \%$ of controls and cases, respectively. The anti-HCV Ab test was positive in $15.22 \%$ of the cases and $4.35 \%$ of the controls.

Regarding signs and symptoms, $94.57 \%$ and $76 \%$ of the cases were hospitalized for abdominal pain and poor general health status or jaundice. The physical exam found an increase in abdominal volume and a jaundice in 60.87 and $10.87 \%$ of the cases, respectively. Alcohol consumers represented $44.57 \%$ of the cases. Edema of the lower limbs, ascitic fluid and hepatomegaly was found in $55.43,68.48$ and $97.83 \%$ of the cases, respectively.

Biological parameters are summarised in Table 2.

The serum transaminases, gamma glutamyl transpeptidases the alkaline phosphatases, bilirubin and alpha foeto-protein were in general higher among at least $70 \%$ of the cases whereas the hemoglobin level was lower in $70.33 \%$ of them.

In bivariate analysis (Table 3), coming from an area other than Ouagadougou the capital city was a statistically a significant risk factor for the primary liver cancer; the unadjusted odd ratio (UOR) was 8.06 and 6.20 for residents of other provincial capitals or of rural area, respectively. The statistically significant protective factors were negative HbsAg (UOR: 0.05) or being an employee in the private or public formal sector (UOR: 0.09).

In a multivariate analysis (Table 3), being 50 years or older, HbsAg chronic carrier, farmer or working in the informal sector or living in a provincial capital were the main statistically significant risk factors to develop primary liver cancer.

\section{Discussion}

The standard profile of a liver cancer patient in our study was a male individual, aged more than 35 , farming or working in the non-formal sector, living in semi-rural or rural area and was a chronic carrier of HbsAg. In general, he visited the doctor for abdominal pain or an abdominal tumour, or a poor health status.

Studies realized in Sub Saharan Africa and beyond described the same profile. Especially, a previous study realized in Ouagadougou in 2014 found a sex ratio of $3.4,{ }^{11} 2.7$ in Abidjan in Ivory Coast, ${ }^{12} 2.3$ in 
Table 1

Socio-demographic and qualitative clinical characteristics of the participants.

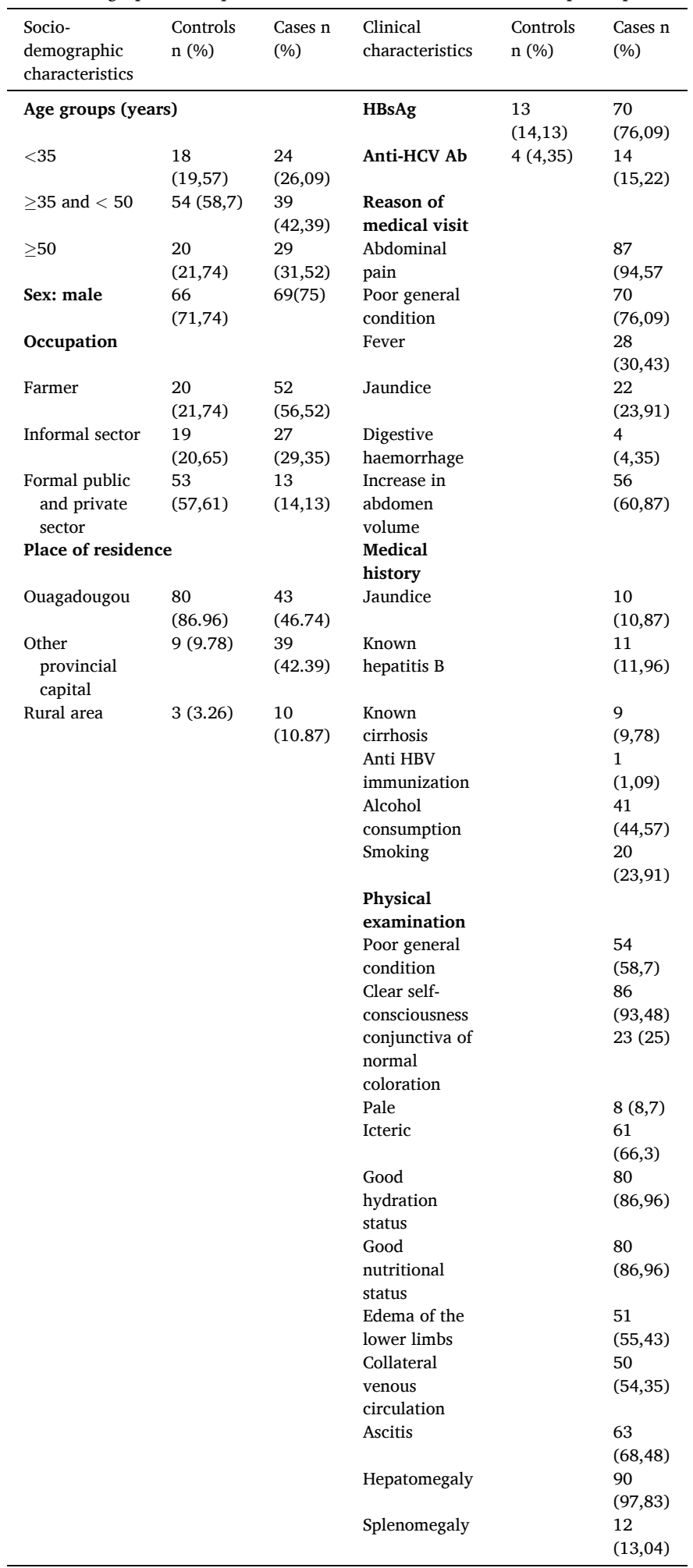

Central Africa ${ }^{13}$ and up to 4.2 in South Africa. ${ }^{14}$ In South Africa, the sex ratio was higher among cases born in rural area (4.2) compared to those born in urban setting (1.6). It was also higher among older people (5 among those older than 40 years and 3 among those aged less than 40 years. ${ }^{15}$ In the different studies, liver cancer occurred in general after 30 years of age ${ }^{11}$ Abdominal pain or tumour as well as the deterioration of the general health status was the main reasons to visit the doctor. ${ }^{11,12}$
Table 2

Blood tests in cases.

\begin{tabular}{|c|c|c|c|}
\hline Tests (n) & Median (P25-P75) & Higher & lower \\
\hline \multicolumn{4}{|l|}{ Serum transaminases } \\
\hline $\operatorname{ASAT}^{\mathrm{a}}(89)$ & $139(88-233)$ & $\begin{array}{l}85 \\
(95,51)\end{array}$ & \\
\hline $\operatorname{ALAT}^{\mathrm{b}}(90)$ & $58.5(37-124.5)$ & $\begin{array}{l}68 \\
(75,56)\end{array}$ & \\
\hline Gamma GT $^{c}(81)$ & $300(151-538)$ & $\begin{array}{l}77 \\
(95,06)\end{array}$ & \\
\hline Alkaline Phosphatases (78) & $202.5(115-428)$ & $\begin{array}{l}56 \\
(71,79)\end{array}$ & \\
\hline Prothrombine (84) & 59.95 (51-68.25) & $\begin{array}{l}67 \\
(79.76)\end{array}$ & \\
\hline \multicolumn{4}{|l|}{ Bilirubine } \\
\hline Total bilirubin (79) & $78(27.5-234)$ & $\begin{array}{l}66 \\
(83.54)\end{array}$ & \\
\hline Conjugated bilirubin (79) & $54.29(14.8-139.6)$ & $\begin{array}{l}67 \\
(84.81)\end{array}$ & \\
\hline Urea (58) & $4.69(3.3-8.4)$ & $\begin{array}{l}14 \\
(24.14)\end{array}$ & \\
\hline Creatinine (85) & 73.5 (56.9-105) & $\begin{array}{l}18 \\
(21.18)\end{array}$ & \\
\hline Blood sugar (79) & $5.5(4.2-6.3)$ & $\begin{array}{l}14 \\
(17.72)\end{array}$ & $\begin{array}{l}11 \\
(13.92)\end{array}$ \\
\hline Alpha foeto protein (89) & $\begin{array}{l}8661.66 \\
(1054-35005.2)\end{array}$ & $\begin{array}{l}85 \\
(95.51)\end{array}$ & \\
\hline Hemoglobin level (91) & $10.3(8.3-12.1)$ & & $\begin{array}{l}64 \\
(70.33)\end{array}$ \\
\hline $\begin{array}{l}\text { Number of white blood cells } \\
\text { (91) }\end{array}$ & $9.1(6.7-13)$ & $\begin{array}{l}36 \\
(39.56)\end{array}$ & \\
\hline HBV viral load (9) & 9634 (6843-23865) & & \\
\hline
\end{tabular}

${ }^{a}$ Aspartate aminotransferases.

b Alanine aminotransferases.

${ }^{\text {c }}$ Gamma glutamyl transpeptidases.

Table 3

Bivariate and multivariate logistic regression of risk factors for the primary liver cancer.

\begin{tabular}{lll}
\hline Risk factors & Unadjusted odd ratio & Adjusted odd ratio \\
\hline $\begin{array}{l}\text { Sex: female } \\
\text { Age groups }\end{array}$ & $0.85(0.44 ; 1.63)$ & $0.55(0.18 ; 1.64)$ \\
$\quad<35$ years & 1 & 1 \\
$\geq 35$ years and $<50$ years & $0.54(0.26 ; 1.13)$ & $1.42(0.45 ; 4.45)$ \\
$\geq 50$ years & $1.09(0.47 ; 2.51)$ & $7.22(1.72 ; 30.20)$ \\
Professional categories & & \\
Farmers or other & 1 & 1 \\
Informal sector & $0.55(0.25 ; 1.19)$ & $1.02(0.31 ; 3.40)$ \\
Private or public formal sector & $0.09(0.04 ; 0.21)$ & $0.18(0.06 ; 0.59)$ \\
Area & & \\
Ouagadougou & 1 & 1 \\
Other provincial capitals & $8.06(3.57 ; 18.20)$ & $9.68(2.82 ; 33.29)$ \\
Rural area & $6.20(1.62 ; 23.74)$ & $5.76(0.89 ; 37.26)$ \\
HBsAg: negative & $0.05(0.02 ; 0.11)$ & $0.04(0.01 ; 0.11)$ \\
VHC AB: negative & $0.79(0.31 ; 2.04)$ & \\
\hline
\end{tabular}

Consumption of alcohol was found in $23.3 \%$ of the patients from an Ivorian study, ${ }^{12}$ lower than the $44.6 \%$ registered in our series. Regarding the biological assessment, the alpha foeto protein and the transaminases were constantly higher as per the most studies on this topic. Anaemia was found in most of the cases participating at the studies.

\subsection{The primary liver cancer's risk factors}

\subsubsection{The participants' age}

In several Sub Saharan African studies, the age of predilection for the HCC was around 50 years ${ }^{11-13}$; this finding was comparable to our own findings. With respect to the risk of developing a primary liver cancer, a Ghanaian case-control study that included 276 participants of which 38 cases, 136 negative controls (neither HBV nor HCV infection nor any other liver pathology) and 102 positive controls (HBV or HCV positive 
but without liver disease), found an odd ratio of 0.3 in favour of the 25-34 year old group as compared to the group of more than 45 years. ${ }^{16}$ In an international multicentre cohort study with a retrospective data collection over 10 years (2006-2016), including 2566 HCC patients from 21 tertiary health care centres, the mean age at the HCC diagnosis time was 46 years (interquartile interval: $36-58$ ); though the analysis was stratified by the aetiology (HBV Vs HCV), this age was younger than in Egypt (58 years; IQI: 53-63). The authors suggested that the younger age at the occurrence of HCC in Sub Saharan Africa would be associated with genetic and environmental factors. ${ }^{14,17}$ A systematic review of HCC case series also concluded at a younger age at the occurrence of HBV-associated HCC in Sub Saharan Africa as well as in Asia. ${ }^{18}$ This situation would be associated with the genotype E and A1, which appears as a genetic feature specific to chronic African HBV carriers. ${ }^{19}$ In a letter to the editorial board, Yusuke suggested that such a median age might be influenced by the population age structure. As a matter of fact, the median age in Sub Saharan Africa (18 years) was younger than the median age in Egypt (25 years). This difference could imply higher risks of competitive causes of deaths. ${ }^{20}$

Regardless of the age structure of a population, HCC cases can be found in younger people. Among children, cases are more frequent in the subgroup of adolescents aged 10-14 years. These paediatric cases occur in adults-HCC-high-prevalence areas, of which Sub Saharan Africa and more specifically Western Africa. ${ }^{21}$ Paediatric HCC cases occur among chronic carriers of HBV. In this context HBV carriage starts during the first 5 years of life. ${ }^{22,23}$ The younger the child when he acquired the HBV infection, the higher the probability of him becoming a chronic carrier. $^{24,25}$

\subsubsection{The HBsAg carriage}

Regarding the chronic carriage of $\mathrm{HbsAg}$, the results of several studies show percentages of HBsAg chronic carriers that were comparable to our own findings: in Ivory Coast $63.3 \%,{ }^{12} 65.90 \%$ in Central Africa, ${ }^{13} 74.8 \%$ in a previous study in Burkina Faso ${ }^{11}$ and $55 \%$ in a representative sample of Sub Saharan African population. ${ }^{14}$ In Sub Saharan Africa, $47 \%$ of HCC cases and $60-80 \%$ in the rest of the world would be associated with the HBV. ${ }^{5,26}$ In Central Africa, the risk of developing an HCC was higher in HBV-infected group compared to the HBV-free one (OR: 15.98; 95\% CI: 6.19-41.25). The risk is higher in case of co-infection with the delta virus (OR: 29.3; 95\% CI: 4.1-1231). ${ }^{13}$ In a case-control study implemented in Western Africa in reference hospitals of Abidjan (Ivory Coast), Bamako (Mali) and Lomé (Togo), the excessive consumption of alcohol, the HBV or HCV infections were significant risk factors of HCC with odds ratios as follow, respectively: 4.5 (CI 95\%: 1.1-18.5), 62.5 (CI 95\%: 20.5-190.7) and 35.9 (95\% CI:10.0-130.3). ${ }^{9}$

\subsubsection{Living in rural area, farming or working in the non-formal sector}

In our study, living in rural area was a risk factor for HCC. The same risk factor was identified in a case-control study with 150 cases of HCC among Black South African. In this study, 65.3\% of the cases were born in rural area $(p=0.03)$. However no difference was reported regarding the place of residence either in rural or urban area ${ }^{15}$ Surprisingly, in this study no significant difference was observed with respect to the chronic carriage of the HbsAg. This situation suggests that the lifestyle in rural area could bear more risks of HCC occurrence, especially through an increased exposure to aflatoxin. Aflatoxins are produced by fungi of the types Aspergillus flavus or parasiticus. These are frequent contaminants of food such as peanuts, milk and maize in tropical areas in LMICs. ${ }^{16,27} \mathrm{~A}$ case-control study implemented in Ghana found that HCC cases had 2.29 times more risk to report an aflatoxin contamination. ${ }^{16}$ Alcohol consumption as well as aflatoxin were risk factors for HCC in a study in Ivory Coast. ${ }^{12}$ The data on these risk factors were not available in the blood bank's registries in Ouagadougou for the current research.

The profession of farming as a risk factor identified in our study could have the same explanations as those associated with rural area, farming being the most popular job in such area. Farming as well as working in the informal sector means in general lower socio-economic status in Burkina Faso. Yet, several studies also established an association between lower socio-economic status and HCC. ${ }^{28}$ Specifically in France, a statistically significant incidence gradient, increasing with social deprivation has been observed for stomach, liver, lips-mouth-pharynx and lungs cancers for both genders. ${ }^{28}$ At the contrary, a study implemented by the international agency for research on cancer in 2018 found that liver cancers would be less associated to social inequities than other cancers. ${ }^{29}$ Accordingly, only $16.8 \%$ of Ivorian patients were from lower socio-economic status at the opposite of our study where the majority of the participants had precarious employment. $^{12}$

\subsection{The importance of the study}

Burkina Faso like the other sub-Saharan African countries is very affected by HBV and HCV infections as well as a heavy alcoholism including adulterated alcohol in the poorer and younger categories of the society. To the best of our knowledge, no etiologic study has been carried out on the HCC in the country. The main strength of this study was to determine, based on evidence, some of the important risk factors of HCC in Burkina Faso context. Implementing rigorously the casecontrol method, we were able to identify that the main risk factors for liver cancer were to be an HBsAg carrier, being aged 35 years or older and being from the lower socio-economic status layer of the society. These data are much helpful when it comes to elaborate prevention and screening strategy in order to avoid the final step which is the disease itself.

\subsection{The study's limitations}

We implemented a case-control study with retrospective data collection. Some important variables were unavailable and were not studied both among cases and controls. In the cases' medical files, factors such as aflatoxin exposure and the co-infection with the delta-virus were not reported. Because many cases were people in need, only a few of them were able to pay for the required lab analyses including the HBV viral load. Variables including smoking status, alcohol consumption as well as the HBV viral load in HbsAg positive controls, were not collected. Therefore, we did not include these variables in the multivariate model. Specifically we were not able to run sensitivity analyses in order to determine the contribution of the HBV viral load in the occurrence of the HCC. However, our study confirms several socio-demographic characteristics as risk factors in perfect agreement with previous studies.

\section{Conclusion}

In general in Burkina Faso, HCC patients went to visit health care workers at an advanced stage of the disease. The chronic carriage of the $\mathrm{HbsAg}$, living in rural area and being from the lower socio-economic status layer were the main risk factors of HCC.

It is important to implement prospective investigations to confirm the role of the identified risk factors and to determine the role of aflatoxin and alcohol in order to design thorough policy to prevent HCC. In the meantime our best tools to reduce the incidence and the mortality by HCC include i) preventing the HBV infection by implementing an efficient immunization scheme including the birth dose administration; ii) managing adequately the cases of HBV and HCV infections.

\section{Author contribution statement}

Eric Nagaonlé Somé: Designed the study, supervised the study, run the statistical analyses; drafted the article.

Alice Nanelin Guingané: Drafted the article, contributing a great insight on HCC.

Bertrand Méda: Drafted the article; Reviewed and approved the 
article.

Herman Ouédraogo: Designed the study, collected and entered the data, reviewed and approved the article.

Grissoum Tarnagda: Reviewed and approved the article.

Séni Kouanda: Designed the study, supervised the study, reviewed and approved the article.

Roger Sombié: Designed the study, supervised the study, reviewed and approved the article.

\section{Source of funding}

This research did not receive any specific grant from funding agencies in the public, commercial, or not-for-profit sectors.

\section{Declaration of competing interest}

None.

\section{Acknowledgement}

We are much grateful to the staff of both the gastro-enterology department who contributed greatly to and facilitated the data collection. We want also to thank the administration of the university teaching hospital Yalgado Ouedraogo who provided all permission to make possible the data collection.

\section{References}

1 Mak D, Kramvis A. Epidemiology and aetiology of hepatocellular carcinoma in Sub Saharan Africa. Hepatoma Res. 2021. https://doi.org/10.20517/2394-5079.2021.15.

2 Mukthinuthalapati V, Abdelaziz A, Sewram V, et al. Hepatocellular carcinoma in subSaharan Africa. JCO Global Oncol. 2021;7:756-766. https://doi.org/10.1200/ GO.20.00425.

3 Dakurah OB, Tamandjou CRT, Zunza M, Preiser W, Maponga TG. Viral hepatitis associated hepatocellular carcinoma on the African continent, the past, present, and future: a systematic review. BMC Cancer. 2021;21(1):715. https://doi.org/10.1186/ s12885-021-08426-y. PubMed PMID: 34144696; PubMed Central PMCID: PMCPMC8214285.

4 Fattovich G, Bortolotti F, Donato F. Natural history of chronic hepatitis B: special emphasis on disease progression and prognostic factors. J Hepatol. 2008;48(2): 335-352. https://doi.org/10.1016/j.jhep.2007.11.011. PubMed PMID: 18096267.

5 Llovet JM, Kelley RK, Villanueva A, et al. Hepatocellular carcinoma. Nat Rev Dis Prim. 2021;7(1):6. https://doi.org/10.1038/s41572-020-00240-3. PubMed PMID: 33479224.

6 Cancer WIAfRo. Cancer Today, population factsheet. In: Burkina Faso. IARC scientific publications; 2018:1-2. http://gco.iarc.fr/today/data/factsheets/populations/854 -burkina-faso-fact-sheets.pdf, 20th January 2020.

7 Breakwell L, Tevi-Benissan C, Childs L, Mihigo R, Tohme T. The status of hepatitis B control in the African region. Pan African Med J. 2017;27(suppl 3). https://doi.org/ 10.11604/pamj.supp.2017.27.3.11981, 17.

8 Shimakawa Y, Lemoine M, Njai HF, et al. Natural history of chronic HBV infection in West Africa: a longitudinal population-based study from the Gambia. Gut. 2016;65 (12):2007-2016. https://doi.org/10.1136/gutjnl-2015-309892. PubMed PMID: 26185161.

9 Jaquet A, Tchounga B, Tanon A, et al. Etiology of hepatocellular carcinoma in West Africa, a case-control study. J. Int. Cancer. 2018;143(4):869-877. https://doi.org/ 10.1002/ijc.31393. PubMed PMID: 29569722; PubMed Central PMCID: PMCPMC6041181.

10 Sangaré L, Sombié R, Combasséré A, et al. Transmission anténatale du virus de l'hépatite B en zone de prévalence modérée du VIH, Ouagadougou, Burkina Faso. Bull Soc Pathol Exot. 2009;102(4):226-229. https://doi.org/10.3185/pathexo3393.
11 Mandé AR. Le cancer primitif du foie: aspects épidémiologiques, diagnostiques, thérapeutiques et évolutifs au centre hospitalier universitaire Yalgado Ouédraogo. [Thèse de doctorat en médecine]. vol. 246. UFS/SDS Section médecine Université de Ouagadougou; 2014:159.

12 M'Bengue AK, Doumbia M, Denoman SR, Ouattara DN, Adoubi I, Pineau P. A major shift of viral and nutritional risk factors affects the hepatocellular carcinoma risk among Ivorian patients: a preliminary report. Infect Agents Cancer. 2015;10:18. https://doi.org/10.1186/s13027-015-0013-1. PubMed PMID: 26131017; PubMed Central PMCID: PMCPMC4486136.

13 Amougou MA, Noah DN, Moundipa PF, Pineau P, Njouom R. A prominent role of Hepatitis D Virus in liver cancers documented in Central Africa. BMC Infect Dis. 2016; 16(1):647. https://doi.org/10.1186/s12879-016-1992-2. PubMed PMID: 27821080; PubMed Central PMCID: PMCPMC5100184.

14 Yang JD, Mohamed EA, Aziz AOA, et al. Characteristics, management, and outcomes of patients with hepatocellular carcinoma in Africa: a multicountry observational study from the Africa Liver Cancer Consortium. Lancet Gastroenterol Hepatol. 2017;2 (2):103-111. https://doi.org/10.1016/s2468-1253(16)30161-3.

15 Mak D, Babb de Villiers C, Chasela C, Urban MI, Kramvis A. Analysis of risk factors associated with hepatocellular carcinoma in black South Africans: 2000-2012. PLoS One. 2018;13(5), e0196057. https://doi.org/10.1371/journal.pone.0196057. PubMed PMID: 29718992; PubMed Central PMCID: PMCPMC5931658.

16 Afum C, Cudjoe L, Hills J, et al. Association between aflatoxin M(1) and liver disease in HBV/HCV infected persons in Ghana. Int J Environ Res Publ Health. 2016;13(4): 377. https://doi.org/10.3390/ijerph13040377. PubMed PMID: 27043586; PubMed Central PMCID: PMCPMC4847039.

17 Yang JD, Roberts LR. Early age at diagnosis of hepatocellular carcinoma in subSaharan Africa - authors' reply. Lancet Gastroenterol Hepatol. 2017;2(6):394. https:// doi.org/10.1016/s2468-1253(17)30107-3.

18 de Martel C, Maucort-Boulch D, Plummer M, Franceschi S. World-wide relative contribution of hepatitis B and C viruses in hepatocellular carcinoma. Hepatology. 2015;62(4):1190-1200. https://doi.org/10.1002/hep.27969. PubMed PMID: 26146815; PubMed Central PMCID: PMCPMC5019261.

19 Bannister EG, Yuen L, Littlejohn M, et al. Molecular characterization of hepatitis B virus (HBV) in African children living in Australia identifies genotypes and variants associated with poor clinical outcome. J Gen Virol. 2018;99(8):1103-1114. https:// doi.org/10.1099/jgv.0.001086. PubMed PMID: 29932395.

20 Shimakawa Y, Lemoine M. Early age at diagnosis of hepatocellular carcinoma in subSaharan Africa. Lancet Gastroenterol Hepatol. 2017;2(6):393. https://doi.org/ 10.1016/s2468-1253(17)30109-7.

21 Stefan C, Bray F, Ferlay J, Liu B, Maxwell Parkin D. Cancer of childhood in subSaharan Africa. Ecancermedicalsci. 2017;11:755. https://doi.org/10.3332/ ecancer.2017.755. PubMed PMID: 28900468; PubMed Central PMCID: PMCPMC5574662.

22 Khanna R, Verma SK. Pediatric hepatocellular carcinoma. World J Gastroenterol. 2018;24(35):3980-3999. https://doi.org/10.3748/wjg.v24.i35.3980. PubMed PMID: 30254403; PubMed Central PMCID: PMCPMC6148423.

23 Kelly D, Sharif K, Brown RM, Morland B. Hepatocellular carcinoma in children. Clin Liver Dis. 2015;19(2):433-447. https://doi.org/10.1016/j.cld.2015.01.010. PubMed PMID: 25921672.

24 Mavilia MG, Wu GY. Mechanisms and prevention of vertical transmission in chronic viral hepatitis. Epub 2017/07/01 J Clin Transl Hepatol. 2017;5(2):119-129. https:// doi.org/10.14218/JCTH.2016.00067. PubMed PMID: 28660149; PubMed Central PMCID: PMCPMC5472932.

25 Spearman C, Afihene M, Ally R, et al. Viral hepatitis in sub-Saharan Africa 1: hepatitis B in sub-Saharan Africa: strategies to achieve the 2030 elimination targets. Lancet. 2017;2:900-909. https://doi.org/10.1016/S2468-1253(17)30295-9.

26 Ganem D, Prince AM. Hepatitis B virus infection - natural history and clinical consequences. N Engl J Med. 2004;350:1118-1129.

27 Ahlberg S, Grace D, Kiarie G, Kirino Y, Lindahl J. A risk assessment of aflatoxin M1 exposure in low and mid-income dairy consumers in Kenya. Toxins. 2018;10(9). https://doi.org/10.3390/toxins10090348. PubMed PMID: 30158473; PubMed Central PMCID: PMCPMC6162552.

28 Bryere J, Dejardin O, Launay L, Colonna M, Grosclaude P. (Francim) elRfdrdc. Socioéconomic environment and cancer incidence in France. BEH. 2017;4:68-77.

29 Centre international de Recherche sur le Cancer. Les cancers attribuables au mode de vie et à l'environnement en France métropolitaine in: Facteurs socio-économiques. Lyon: Centre international de Recherche sur le Cancer; 2018:189-216. 